\title{
Can Life History Trade-Offs Explain the Evolution of Short Stature in Human Pygmies? A Response to Migliano et al. (2007)
}

\author{
NOÉMIE S. A. BECKER, ${ }^{1}$ PAUL VERDU, ${ }^{1}$ BARRY HEWLETT, ${ }^{2}$ AND SAMUEL PAVARD ${ }^{1}$
}

\begin{abstract}
Walker et al. ["Growth rates and life histories in twenty-two smallscale societies," Am. J. Hum. Biol. 18:295-311 (2006)] used life history theory to develop an innovative explanation for human diversity in stature. Short stature could have been selected for in some human populations as a result of the advantage of an earlier growth cessation and earlier reproduction in a context of high mortality. Migliano et al. ["Life history trade-offs explain the evolution of human pygmies," Proc. Natl. Acad. Sci. USA 104:20,216-20,219 (2007)] recently published an important article that tested this hypothesis to explain short stature in human pygmy populations. However innovative this work may be, we believe that some of the data and results presented are controversial if not questionable. As problematic points we note (1) the use of an arbitrary threshold of height $(155 \mathrm{~cm})$ to categorize populations into pygmies and nonpygmies; (2) the use of demographic data from Philippine pygmy groups that have experienced dramatic cultural and environmental changes in the last 20 years, and (3) the use of demographic data concerning African pygmy groups because good systematic data on these groups are not available. Finally, we report here mathematical errors and loopholes in the optimization model developed by Migliano and colleagues. In this paper we suggest alternative trade-offs that can be used to explain Migliano's results on more reliable bases.
\end{abstract}

Raymond Pearl, the founder of Human Biology, was concerned throughout his career with the "proper measure of man" (Sokal 2004), probably his main legacy to anthropological sciences. Because the Proceedings of the National Academy of Sciences does not publish commentaries, we thought that Human Biology was an appropriate place to publish a commentary on a research article by Migliano et al. (2007), who proposed to interpret human diversity in stature and the human pygmy phenotype in light of life history theory. However innovative and challenging this \footnotetext{
France.

${ }^{1}$ Ecoanthropology and Ethnobiology, UMR 7206, Musée de l'Homme, 17 place du Trocadéro, 75016 Paris,

${ }^{2}$ Department of Anthropology, Washington State University, Vancouver, WA 98686.

All authors contributed equally to this work.

The editorial process for this paper was independently assumed by Michael H. Crawford to avoid any conflict of interest.
}

Human Biology, February 2010, v. 82, no. 1, pp. 17-27.

Copyright (C) 2010 Wayne State University Press, Detroit, Michigan 48201-1309 FERTILITY.

KEY WORDS: PYGMIES, HEIGHT, LIFE HISTORY, DEMOGRAPHY, MORTALITY, 


\section{8 / BECKER ET AL.}

work may be, some features and results presented by its authors seem controversial. Here, we aim to stimulate the growing debate raised by this article since its publication (Perry and Dominy 2009) in order to improve potential future work in this promising line of research.

The question of small stature in human pygmy populations has been extensively debated in the anthropological literature. Several hypotheses propose that pygmy stature is an adaptation to environmental pressures (e.g., nutritional, thermoregulatory, metabolic, or energetic pressures) (Perry and Dominy 2009). Following the work of Hill and Hurtado (1996), Walker et al. (2006) used life history theory to develop an alternative explanation. Walker and colleagues hypothesized that short stature in pygmies was a consequence of high mortality rates; in contexts of high mortality, earlier growth cessation and reproduction onset may be adaptive. Migliano et al. (2007) published an important paper to test this hypothesis. The investigators explored two questions: Do pygmy growth rates and final stature reflect nutritional stress, and is earlier onset of reproduction (associated with growth cessation) optimal in pygmies as a result of higher mortality, thus explaining the pygmies' shorter stature?

Migliano et al. (2007) compared growth curves of pygmy and U.S. women and found that pygmies grew faster than undernourished U.S. citizens but that they ceased to grow earlier. Migliano and colleagues concluded that small stature in pygmies was due to a shorter duration of growth rather than to a lower growth rate and that nutritional stress was not a likely explanation for pygmy short stature.

Migliano et al. (2007) further presented data on survival and fertility in pygmy and nonpygmy populations. First, they found a lower survivorship and an earlier age-specific fertility in pygmy populations. Second, they found a positive correlation between height and fertility in pygmy women. Third, they incorporated age trajectories of survival and fertility and correlation between height and fertility into a life history model. In this model, growth cessation at maturity was the key factor that regulated the trade-off between risk of death before first reproduction and fertility after maturity. The investigators thus tested whether earlier growth cessation was selected for in pygmies in order to decrease the risk of dying before reproduction. The lower height at maturity came at the cost of a loss in fertility, however. Migliano and colleagues calculated the optimal age at maturity for the Aeta pygmies from the Philippines and for three nonpygmy populations (using previously published data): the South American Ache (Hill and Hurtado 1996), the Namibian !Kung (Howell 1979), and Gambian rural women (Allal et al. 2004). They found an earlier optimal age at first reproduction in the Aeta (15 years) than in the nonpygmy groups (18-19 years). They concluded that an early onset of reproduction was optimal in pygmies even if the resulting smaller adult size induced a reduction of fertility.

Life history theory has been successfully used to explore reproductive scheduling in human populations, such as the optimal age at first and last reproduction (Allal et al. 2004; Shanley and Kirkwood 2001) and the optimal reproduction rate (Mace 1998). With the riddle of pygmy stature being unsolved 
(Perry and Dominy 2009), it was promising to test whether a trade-off between timing in growth and reproductive outcome could explain pygmies' stature (Hill and Hurtado 1996).

Although we are fully aware of the challenges encountered by Migliano et al. (2007), we think that the data and model are insufficient to support their conclusions. Rather, we consider Migliano et al.'s study a promising first step for testing the life history hypothesis in pygmy populations. First, issues arise when an arbitrary height threshold is used to categorize human populations into pygmies and nonpygmies. Second, we question the pygmy demographic data: (1) Philippine pygmies' demography is influenced by recent forces of acculturation (e.g., tuberculosis, alcoholism, forced resettlement), and (2) African pygmy data are still insufficient to construct age-specific survivorship or age-specific fertility schedules. Third, we found mathematical errors and loopholes in the optimization models, and other relevant trade-offs could be considered.

\section{A Height Threshold to Categorize Human Populations into Pygmies and Nonpygmies}

The Greek word pygmy is a measure of size ("a cubit"). Applied to various animal species, it refers to populations that show a reduction in stature compared to the average size of the same species. In human populations there is no gap in size between pygmy and nonpygmy populations, although populations designated as pygmies are found in the lowest extreme of the worldwide variability of stature (Froment 1993). If the life history hypothesis explored by Migliano et al. (2007) is true, then a continuous positive correlation should exist between adult height and mortality rates. Problems inevitably arise when an arbitrary threshold on height is established to distinguish pygmy and nonpygmy populations. If we define the human pygmy phenotype by an average adult male height shorter than $1.50 \mathrm{~m}$, then the Efé from the Eastern Democratic Republic of Congo are the only pygmy population (Schmidt 1905; Schreider 1968). If $1.60 \mathrm{~m}$ is considered (Cavalli-Sforza 1986), more than 200 populations worldwide could be categorized as pygmies (Froment 1993; Hiernaux 1974).

The arbitrary choice of $1.55 \mathrm{~m}$ as the size threshold (Migliano et al. 2007) includes the Namibian!Kung in the nonpygmy category. Migliano et al. (2007) found an optimal age at first reproduction for the !Kung of 19.5 years. Setting the threshold at $1.60 \mathrm{~m}$, following Cavalli-Sforza (1986), however, would have classified the !Kung as pygmies and would therefore have jeopardized Migliano et al.'s (2007) conclusions. Similarly, the Ache were considered nonpygmies by Migliano et al. (2007) but could be divided into two subpopulations: Northern Ache pygmies (1.53 $\mathrm{m}$ on average) and Southern Ache nonpygmies (1.60 m on average) (K. Hill, personal communication, 2009).

In Central Africa, cultural criteria, such as the way of life, identity with forest, language, music, or social interactions, are often used to distinguish pygmies from nonpygmies (Bahuchet 1992a, 1993a, 1993b; Froment 1993). By 
doing so, some populations taller than $1.55 \mathrm{~m}$ are designated as pygmies. For instance, the Twa (literal translation from Bantu languages is "pygmy") of the Western Democratic Republic of Congo are $1.61 \mathrm{~m}$ tall on average but are nevertheless designated as pygmies (Froment 1993; Pagezy 1988). Such complex cultural categorization has recently been explored from a genetics perspective in nine western Central African pygmy populations and their respective nonpygmy neighbors (Verdu et al. 2009). Verdu and colleagues found strong genetic evidence for a recent common origin (about 2,800 years ago) of nine western Central African populations categorized as pygmies following numerous cultural criteria. Among them were populations taller than $1.55 \mathrm{~m}$ (Froment 1993; Verdu 2009; Verdu et al. 2009).

\section{Issues with Demographic Data}

The demographic data collected by Migliano et al. (2007) on Aeta and Batak pygmies are an important contribution to anthropological demography. However, the demographic data of the Batak, Agta, and Aeta populations should be used carefully when testing long-term evolutionary processes because recent sociocultural changes may have strongly affected their mortality and fertility.

For the Batak, Migliano constructed mortality and fertility schedules using Eder's data (Eder 1987; Migliano 2005). However, Eder (1987) indicated that the Batak's high mortality and low fertility, resulting in a strong population decline since 1981, were in fact due to intermarriages with lowlanders, land loss, and decline in cultural identity. Similar issues arise with the Agta demographic data used by Migliano and researched by Early and Headland (1998). The high adult mortality rates in the Casiguran Agta were due to tuberculosis, malnutrition, and alcohol-related deaths and homicides (Headland 1989). Tuberculosis was the single biggest killer among Agta adults, and 6\% of all adult deaths and $20 \%$ of adult male deaths were alcohol related (Headland 1989). The demographic data for the Philippines Aeta were collected and presented for the first time by Migliano (2005). These Aeta were removed from their traditional lands in 1991 and moved to urban settlements near cities. Since then they have not been able to hunt and gather and have had access to Western medicine (Migliano 2005). Living for nearly 20 years in forced urban resettlements likely influenced the demography of the Aeta, who originally lived in forest areas. The higher mortality currently observed in these three populations may not reflect their past demography, when short stature evolved. Past demography of these populations may be extrapolated by removing recent causes of death within a competitive risk modeling.

On the other hand, African pygmy populations_Aka (often called Biaka), Mbuti, and Efé-are particularly relevant for testing long-term evolutionary hypotheses. Ethnographers and biological anthropologists do not characterize African pygmies as being near extinction, do not identify alcoholism and tuberculosis as primary causes of death (Bahuchet 1992a, 1993b; Cavalli-Sforza 1986; Hewlett 1996; Joiris 2003), and do not suggest that malnutrition is common (Bahuchet 
et al. 1991; Froment 2001; Hladik et al. 1989; Koppert et al. 1993; Pagezy 1988). However, African demographic data suffer from another issue: Focused and systematic studies have not been conducted on these populations (Bahuchet 1992b; Cavalli-Sforza 1986).

Efé and Mbuti pygmies, grouped as a single "Eastern African pygmy" population by Migliano et al. (2007) in their Figure 2 (but reported separately in the text), are linguistically, culturally, and demographically very different (Hewlett 1996). The data for these two groups were extracted from Schebesta's (1938) general census data. However, Migliano et al. (2007) could have used Bailey's (1985) more recent demographic data on this eastern African pygmy group, leading to different conclusions. Indeed, Bailey (1985) estimated an infant mortality rate of 14.0 and a child mortality rate of 22.0, values that are substantially lower than those for all other pygmy and nonpygmy groups cited by Migliano et al. (2007). Furthermore, survivorship to age 15 among the Efé is $78 \%$ (Bailey 1985), but it is $44 \%$ considering Schebesta's older census data (1938) used by Migliano et al. (2007).

Migliano et al. (2007) refer respectively to Migliano and Weiss for the Efé and the Mbuti life expectancies. In fact, to our knowledge, life tables based on actual data have not been reported for either one of these populations. Migliano et al. (2007) reconstructed the life tables using Weiss's theoretical demographic models (Weiss 1973a, 1973b), which were based on census data (e.g., number of children and adults in camps) collected by ethnographers. Unfortunately, these models assume stable age-specific mortality and a stable age structure in the population, which is unlikely for African pygmies. These model-based life tables were built using the African demographic data on "Western pygmies" (including the Aka) from Cavalli-Sforza (1986) and on "Eastern pygmies" from Turnbull (1986) for the Mbuti and Schebesta (1938) on the Efé (Migliano 2005). None of these ethnographers or anthropologists recorded birthdates over time; nor did they try to rank individuals by age or collect detailed reproductive histories from a large number of individuals. Moreover, Cavalli-Sforza was clear about the quality of his demographic data: "We have no totally satisfactory estimates of mortality rates in pygmies" (1986: 376) and "the analysis of fertility, like that of mortality, suffers greatly from the difficulty of knowing ages reliably, and therefore one is unable to compute age-specific fertilities" (1986: 39). Froment (1993) also highlighted the challenges of building reliable growth curves for African pygmy populations in the absence of precise age estimates. The actual data on pygmy growth are indeed contradictory; Bailey's (1991) study showed that growth was slower in Efé pygmy children from birth to age 5 than in farmers, whereas this pattern was not evident among the Aka (Van de Koppel and Hewlett 1986).

On an ethnographic note, most Central African nonpygmy farmers view pygmies as being incredibly fertile and as having infants healthier than their own (Kazadi 1981; Turnbull 1965). One might suggest that if child mortality was in fact higher in pygmies, then farmers would have had the opposite cultural representation of pygmies' fertility. Anyway, the demographic reality of such cultural representation can only be assessed using quality demographic data. 


\section{Criticisms of the Optimization Models}

Migliano et al. (2007) found a positive correlation between fertility and height for the Efé and the Aeta pygmies. However, it is the relationship between weight and fertility that is largely theorized through models incorporating allometric production function and that holds in most mammal species (Charnov 1991, 1993). Migliano and colleagues failed to estimate such a correlation for the Aeta (see Migliano et al. 2007, Supporting Material). For the Ache population, a positive correlation was found between fertility and weight rather than between fertility and height (Hill and Hurtado 1996), and in the case of Gambian women, no significant effect of height on fertility was identified (Sear et al. 2004). Migliano and colleagues thus incorporated indifferently trade-offs considering height for the nonpygmy populations (Ache and Gambia) and weight for the unique pygmy population (Aeta). This can be a problem because the allometric relationship between height and weight is complex and their age trajectories are different (Howell 1979) and because the relationship between height and fertility is still inductive and may vary widely between populations.

We wonder whether the conclusions drawn by Migliano et al. (2007) would still hold if the investigators had incorporated two additional well-known correlations between fertility and mortality that enhance the advantage of delaying growth cessation and age at first reproduction: (1) Young primiparas have a higher risk of both mother and child death resulting from pregnancy complications than older primiparas do (Friede et al. 1987; Makinson 1985; Rush 2000; Zabin and Kigaru 1998), and (2) taller Gambian women have fewer stillbirths and reduced infant mortality, showing that height is positively correlated with offspring survival (Sear et al. 2004).

Following Hill and Hurtado (1996), Migliano et al. (2007) extended the Lotka-Volterra model (Lotka 1925; Volterra 1926) by incorporating a nonnegative multiplier $H_{\alpha}$ on fertility rates $m_{x}$ into the Euler-Lotka equation (Euler 1760; Lotka 1925), where $\alpha$ is the age at maturity. The magnitude of $H_{\alpha}$ depends on individuals' height at maturity. Fertility as a function of height at maturity $m_{x} H_{\alpha}$ is therefore a monotonic positive function of height at age $\alpha$. This equation [Eq. (1) in Migliano et al. (2007), reproduced in what follows] allowed numerical calculation of the intrinsic rate of population increase $r$ (also called Malthusian parameter):

$1=\sum_{X=0}^{\infty} l_{x} m_{x} H_{\alpha} \exp [-r(x-\alpha+1)]$.

The Malthusian parameter $r$ (taken as a measure of population fitness) was then calculated for an age at maturity $\alpha$ taken between 12 and 30 years, and the optimal age at maturity was the value of $\alpha$ for which $r$ was maximal. Unfortunately, Eq. (1) in Migliano et al. (2007) is wrong. First, it accepts negative ages when $x<(\alpha-1)$. Second, $r$ is rate sensitive; that is, it captures the importance 
of the relative timing of life history events: the age $x-\alpha$ in Eq. (1) by which $r$ is multiplied within the exponential component (the +1 being here to set the first age class to 0 ) must be similar to the corresponding age used for fertility rates and age-specific survival [the age $x$ in $m_{x}$ and $l_{x}$, respectively, in Eq. (1)]. If not, stable population growth rates (intrinsic or finite) and stable population structure are not correctly estimated. Rather than Eq. (1), we believe that the correct equation should be

$$
1=\sum_{x=0}^{\infty} l_{x} m_{x} H_{\alpha} \exp [-r(x+1)]
$$

where $m_{x}=0$ for $x<\alpha$ [because $H_{\alpha}$ is positive for $\alpha>0$; Eq. (4) in Migliano et al. (2007)].

Such an error may be due to mistyping. However, if Migliano and colleagues had applied Eq. (1), they would have strongly overestimated population growth or decline, with individuals producing offspring sooner in Eq. (1) than in Eq. (2). This may explain why the intrinsic rates of population increase $r$ calculated by Migliano et al. (2007) were widely inconsistent with those previously estimated and even unreasonable for some populations. For instance, in the Ache population, $r$ as a function of $\alpha$ was found to be between 0.32 and 0.36 (Migliano et al. 2007). Such values correspond to finite rates of population increases $\lambda$ between $e^{0.32}=1.38$ and $e^{0.36}=1.43$. No human population increases by $38-43 \%$ per year. These estimates are tenfold higher than previous estimates (3.6\% of increase per year; Hill and Hurtado 1996: 101). Similarly, for the !Kung, Migliano et al. (2007) estimated $r$ values (0.015-0.023) that were 10 times larger than Howell's (1979) $r=0.0026$.

We were also concerned about potential loopholes in the optimization framework. First, because the Aeta population is in decline, the $r$ corresponding to the optimal age at maturity $\alpha$ was negative (Migliano et al. 2007, Figure 3). From an evolutionary perspective, one may be skeptical about considering a strategy that leads to population extinction as optimal. As discussed, the decline in the Aeta is likely due to recent lifestyle changes. The Aeta could not have exhibited such a $3 \%$ decline in population size per year for a long period of time; within the last 100 years (about 4-5 generations), they would have fallen in size by $95 \%$.

Rather than comparing strategies optimized for populations exhibiting different demographic regimes, adaptive landscape could be analyzed for variations in parameters "everything else being equal" (Lande 1982). Indeed, no population can grow or decline indefinitely. Ideally, survival and fertility parameters should have been incorporated to obtain a continuum of optimal strategies (from very small to very tall) for a large range of demographic scenarios. Finally, the curve of $r$ as a function of height presented for the Aeta (Migliano et al. 2007, Figure 3) is rather flat around the optimal $\alpha$. From $\alpha=14$ to $\alpha=18$, the magnitude of variation in $r$ is roughly between 0.001 and 0.005 . Long-term evolution should be advocated for such a small effect leading to evolutionary outcomes (and therefore 


\section{4 / BECKER ET AL.}

a constant past demographic regime) as well as accurate demographic estimates (optimum $\alpha$ values being more sensitive to small changes in demographic parameters). Because $\alpha=18$ falls within the range of optimal $\alpha$ values calculated for nonpygmy populations (18 for the Ache, 19.5 for the !Kung, and 18 for the Gambian population), one can therefore wonder whether Migliano and colleagues really succeeded in bringing to light a significant difference in reproductive strategies between populations categorized as pygmies and nonpygmies. To evaluate the significance of such a difference, one could analyze the robustness of the optimums by calculating the secondary derivative $\partial^{2} r / \partial \alpha$ of $r$ with respect to $\alpha$.

\section{Conclusion}

Migliano et al. (2007) explored whether pygmy stature is a biological adaptation resulting from the advantage of reproducing early in a context of high mortality at the cost of a shorter adult height that entails future fertility. Within a model incorporating this trade-off, the investigators calculated an earlier optimal age at first reproduction for the Aeta pygmies (15 years old) than for three nonpygmy populations: the Ache, the !Kung, and Gambian rural women (18-19.5 years old).

However, we have shown that categorizing populations as either pygmies or nonpygmies on the basis of an arbitrary threshold of height can be problematic: (1) It leads to group populations with different demographic features; (2) the populations thus clustered do not necessarily share recent common ancestry; and (3) it fails to explain variation in stature throughout the continuum of height observed in humans.

Migliano has collected important demographic data on the Aeta and Batak populations to test Walker's hypothesis. However the Philippine pygmies are in decline because of recent forces of acculturation. As a consequence, Migliano compared populations exhibiting very different demographic regimes: from a population growing very fast (the Ache) to a population in dramatic decline (the Aeta). In the case of the Aeta, this also led to the consideration as optimal of a life history strategy leading to population extinction.

Concerning African pygmy populations, demographic data are inaccurate largely because of the lack of longitudinal studies and the absence of precise age estimates. In turn, such inaccuracies may have a large effect on the estimated optimum, which makes analyses of the robustness of the optimum essential.

A mathematical mistake has been found in Migliano et al.'s (2007) modeling framework, and problems may arise by considering that height and weight at maturity impact on fertility in a similar way. In future studies, other well-known trade-offs (e.g., one resulting from maternal mortality) should be taken into account because they might highly influence the optimal age at first reproduction.

The application of Charnov's life history theory to explain short stature in humans is innovative and provocative (Walker et al. 2006). Migliano's attempt to test it in pygmies is a promising research angle, although we doubt that the 
study succeeded in demonstrating the role played by life history trade-offs in the evolution of human morphological diversity. We nevertheless hope that this first attempt will encourage further research on the potential implication of life history theory in pygmies' stature. This will require the enrichment of demographic data on pygmy populations, especially those from Africa, including values of agespecific survival and fertility as well as growth patterns.

Acknowledgments We gratefully thank Serge Bahuchet, Philipp Endicott, Alain Froment, Kim Hill, Patrick Pasquet, and Fernando Ramirez-Rozzi for their useful comments and advice, as well as the referees for their helpful reviews.

Received 10 June 2009; revision accepted for publication 1 October 2009.

\section{Literature Cited}

Allal, N., R. Sear, A. M. Prentice et al. 2004. An evolutionary model of stature, age at first birth, and reproductive success in Gambian women. Proc. Biol. Sci. 271:465-470.

Bahuchet, S. 1992a. Dans la forêt d'Afrique Centrale: Les Pygmées Aka et Baka. Paris: Peeters-Selaf.

Bahuchet, S. 1992b. Spatial mobility and access to the resources among the African Pygmies. In Mobility and Territoriality: Social and Spatial Boundaries Among Foragers, Fishers, Pastoralists, and Peripatetics, M. J. Casimir and A. Rao, eds. New York: Berg, 205-257.

Bahuchet, S. 1993a. L'invention des Pygmées. Cah. Etud. Afr. 33:153-181.

Bahuchet, S. 1993b. La rencontre des agriculteurs: Les Pygmées parmi les peuples d'Afrique Centrale. Paris: Peeters-Selaf.

Bahuchet, S., D. McKey, and I. de Garine. 1991. Wild yams revisited: Is independence from agriculture possible for rainforest hunter-gatherers? Hum. Ecol. 19:213-243.

Bailey, R. C. 1985. The Socioecology of Efé Pygmy Men in the Ituri Forest (Zaire). Ph.D. dissertation, Harvard University, Cambridge, MA.

Bailey, R. C. 1991. The comparative growth of Efé pygmies and African farmers from birth to age 5 years. Ann. Hum. Biol. 18:113-120.

Cavalli-Sforza, L. L., ed. 1986. African Pygmies. London: Academic Press.

Charnov, E. L. 1991. Evolution of life-history variation among female mammals. Proc. Natl. Acad. Sci. USA 88:1134-1137.

Charnov, E. L. 1993. Life History Invariants: Some Explorations of Symmetry in Evolutionary Ecology. Oxford: Oxford University Press.

Early, J. D., and T. N. Headland. 1998. Population Dynamics of a Philippine Rainforest People: The San Ildefonso Agta. Gainesville: University Press of Florida.

Eder, J. F. 1987. On the Road to Tribal Extinction: Depopulation, Deculturation, and Adaptive WellBeing Among the Batak of the Philippines. Berkeley: University of California Press.

Euler, L. 1760. Recherches générales sur la mortalité: La multiplication du genre humain. Mem. Acad. Sci. Berlin 16:144-164.

Friede, A., W. Baldwin, P. H. Rhodes et al. 1987. Young maternal age and infant mortality: The role of low birth weight. Public Health Rep. 102:192-199.

Froment, A. 1993. Adaptation biologique et variation dans l'espèce humaine: Le cas des Pygmées d'Afrique. Bull. Mem. Soc. Anthropol. Paris 5:417-448.

Froment, A. 2001. Evolutionary biology and health of hunter-gatherer populations. In Hunter-Gatherers: An Interdisciplinary Perspective, C. Panter-Brick, R. H. Layton, and P. Rowley-Conwy, eds. Cambridge, U.K.: Cambridge University Press, 239-266. 


\section{6 / BECKER ET AL.}

Headland, T. N. 1989. Population decline in a Philippine Negrito hunter-gatherer society. Am. J. Hum. Biol. 1:59-72.

Hewlett, B. S. 1996. Cultural diversity among African Pygmies. In Cultural Diversity Among Twentieth-Century Foragers: An African Perspective, S. Kent, ed. Cambridge, U.K.: Cambridge University Press, v. 1, 215-244.

Hiernaux, J. 1974. The People of Africa. London: Weidenfeld and Nicolson.

Hill, A., and K. Hurtado. 1996. Aché Life History: The Ecology and Demography of a Foraging People. New York: Aldine de Gruyter.

Hladik, C. M., S. Bahuchet, and I. de Garine, eds. 1989. Se nourrir en forêt équatoriale: Anthropologie alimentaire des populations des régions forestières humides d'Afrique. Paris: Unesco-MAB.

Howell, N. 1979. Demography of the Dobe! Kung. New York: Aldine de Gruyter.

Joiris, D. V. 2003. The framework of Central African hunter-gatherers and neighboring societies. Afr. Stud. Monogr. 28(suppl.):57-79.

Kazadi, N. 1981. Méprisés et admirés: L'ambivalence des relations entre les Bacwa (Pygmées) et les Bahemba (Bantu). Africa 51:837-847.

Koppert, G. J. A., E. Dounias, A. Froment et al. 1993. Food consumption in three forest populations of the southern coastal region of Cameroon. In Tropical Forest: People and Food, C. M. Hladik, A. Hladik, O. F. Linares et al., eds. MAB Series, v. 13. London: Parthenon-UNESCO, 295-311.

Lande, R. 1982. A quantitative genetic theory of life-history evolution. Ecology 63:607-615.

Lotka, A. J. 1925. Elements of Physical Biology. Baltimore: Williams \& Wilkins.

Mace, R. 1998. The coevolution of human fertility and wealth inheritance strategies. Phil. Trans. R. Soc. Lond. B 353:389-397.

Makinson, C. 1985. The health consequences of teenage fertility. Fam. Plann. Perspect. 17:132-139.

Migliano, A. B. 2005. Why Pygmies Are Small: Ontogenic Implications of Life History Evolution. Ph.D. dissertation, Department of Biological Anthropology, University of Cambridge, Cambridge, U.K.

Migliano, A. B., L. Vinicius, and M. M. Lahr. 2007. Life history trade-offs explain the evolution of human pygmies. Proc. Natl. Acad. Sci. USA 104:20,216-20,219.

Pagezy, H. 1988. Coping with uncertainty in food supply among the Oto and the Twa living in the equatorial flooded forest near Lake Tumba, Zaire. In Coping with Uncertainty in Food Supply, I. de Garine and G. A. Harrison, eds. Oxford, U.K.: Clarendon Press, 175-209.

Perry, G. H., and N. J. Dominy. 2009. Evolution of the human pygmy phenotype. Tr. Ecol. Evol. 24:218-225.

Rush, D. 2000. Nutrition and maternal mortality in the developing world. Am. J. Clin. Nutr. 72(suppl.):212S-240S.

Schebesta, P. 1938. Die Bambuti-Pygmäen von Ituri, v. 1, Geschichte, Geographie, Umwelt, demographie und Anthropologie der Ituri-Bambuti. Brussels: Oxford University Press.

Schmidt, E. 1905. Die Grösse der Zwerge und die sogennanten Zwervölker. Globus 87:121-125.

Schreider, E. 1968. Growth hormone in African pygmies. Lancet 1(7533):92.

Sear, R., N. Allal, R. Mace et al. 2004. Height and reproductive success among Gambian women [abstract]. Am. J. Hum. Biol. 16:223.

Shanley, D. P., and T. B. Kirkwood. 2001. Evolution of the human menopause. Bioessays 23:282-287.

Sokal, R. R. 2004. Raymond Pearl's legacy: The proper measure of man. Am. J. Hum. Biol. 16:113124.

Turnbull, C. M. 1965. Wayward Servant: The Two Worlds of the African Pygmies. New York: Natural History Press.

Turnbull, C. M. 1986. Survival factors among Mbuti and other hunters of the equatorial African rainforest. In African Pygmies, L. L. Cavalli-Sforza, ed. Orlando, FL: Academic Press, 103-123.

Van de Koppel, J. C. H., and B. S. Hewlett. 1986. Growth of Aka Pygmies and Bangandus of the Central African Republic. In African Pygmies, L. L. Cavalli-Sforza, ed. London: Academic Press, 95-102. 
Verdu, P. 2009. Anthropologie Génétique des Populations d'Afrique Centrale: Histoire du Peuplement Pygmée. Paris: Hommes Natures Sociétés, National Museum of Natural History.

Verdu, P., F. Austerlitz, A. Estoup et al. 2009. Origins and genetic diversity of pygmy hunter-gatherers from western Central Africa. Curr. Biol. 19:312-318.

Volterra, V. 1926. Variazioni e fluttuazioni del numero d'individui in specie animali conviventi. Mem. Acad. Lincei 2:31-113.

Walker, R., M. Gurven, K. Hill et al. 2006. Growth rates and life histories in twenty-two small-scale societies. Am. J. Hum. Biol. 18:295-311.

Weiss, K. M. 1973a. Demographic Models for Anthropology. Memoirs of the Society for American Archaeology 27. Washington, DC: Society for American Archaeology.

Weiss, K. M. 1973b. A method for approximating age-specific fertility in the construction of life tables for anthropological populations. Hum. Biol. 45:195-210.

Zabin, L. S., and K. Kigaru. 1998. The health consequences of adolescent sexual and fertility behavior in sub-Saharan Africa. Stud. Fam. Plann. 29:210-232. 
